${ }^{1}$ Department of Professional Training in Clinical Chemistry, Faculty of Pharmacy with the Division of Laboratory Diagnostics, Wroclaw Medical University ${ }^{2}$ Non-public Health Care Facility Centre for Diabetes and Endocrinology Care, Wroclaw

${ }^{3}$ Department of Toxicology, Faculty of Pharmacy with the Division of Laboratory Diagnostics, Wroclaw Medical University

\title{
The relationship between total body fat and distribution of body fat mass and markers of insulin resistance in young women with normal weight - a pilot study
}

\section{ABSTRACT}

Introduction. Total body fat and body fat distribution are factors closely associated with development of insulin resistance, including subjects with normal body weight and BMI (body mass index).

Objectives. The objective of the study was to determine relation between insulin resistance index and selected parameters of body fat distribution in potentially healthy young females with body mass index below $25 \mathrm{~kg} / \mathrm{m}^{2}$.

Material and methods. Study group consisted of 36 women with a BMI $<25 \mathrm{~kg} / \mathrm{m}^{2}$, who underwent anthropometric measurements, i.e.: height, weight, waist circumference, hip circumference and blood pressure measurement. The segmental body composition was measured by of the use of the bioelectric impedance analysis (BIA). Moreover, oral glucose tolerance test (OGTT) was performed with blood collection in 0,60 and 120 minute of the test. The fasting samples were used for determination of concentrations of glucose, insulin, C-peptide, a total cholesterol, triglycerides, HDL

Address for correspondence:

mgr Izabela Monika Kokot

Zakład Praktycznej Nauki Zawodu Analityka

Wydział Farmaceutyczny z Oddziałem Analityki Medycznej

Uniwersytet Medyczny we Wrocławiu

e-mail: izabela.kokot@umed.wroc.pl

Translation: GROY Translations

Clinical Diabetology 2016, 5, 2, 41-48

DOI: $10.5603 /$ DK.2016.0008

Received: 01.10.2015 Accepted: 01.02.2016 and LDL cholesterol. The following insulin resistance indices were calculated: HOMA-IR, HOMA2-IR, HOMA2$\% B$, HOMA2-\%S and IRI/G.

Results. All the volunteers presented normal glucose tolerance in 120 minute of the OGTT test, as well as normal values of IRI/G index. Moreover, for such parameters as: total cholesterol, HDL and LDL cholesterol, triglycerides and CRP no values outside the reference range were found. C-peptide concentration was found to be significantly correlated with total body fat $(r=0.532 ; p=0.001)$ and trunk fat mass $(r=0.471$; $p=0.004)$.

Conclusions. In the young, non-obese women it seems to be justified to test concentration of glucose and C-peptide while assessing potential insulin resistance with simultaneous examination of the total and trunk body fat. (Clin Diabet 2016; 5, 2: 41-48)

Key words: insulin resistance, body fat weight, bioelectric impedance

\section{Introduction}

In the last several years there was a number of studies conducted to definee detailed criteria of cardiovascular disease, diabetes and metabolic syndrome probability [1-3]. The problem of these diseases is visible in the developed and developing countries, where the largest increase in new cases of the disease is observed and directly related to increasing number of obese people. Excessive body weight caused by 
increase in body fat - especially the abdomen one is the main cause of increasing tissue insulin resistance [4]. This relationship is also found in people with normal body weight and BMl (body mass index), which indicates that fat tissue distribution is a key factor in development of metabolic disorder [5-7], in increasingly younger people [8]. Insulin resistance seems to be one of the factors related to reproduction disorders, including risk of spontaneous abortion $[9,10]$. Tissue insulin resistance is found not only in overweight or obese women, or ones suffering from polycystic ovary syndrome [11], but also in potentially healthy women with normal BMI [10].

The golden standard for determination of insulin resistance is euglycemic clamp, which is technically difficult and very burdensome for the body. In clinical conditions it is rarely used due to difficult procedure and high costs. In practice, indirect methods for assessment of insulin resistance are used the most often, which are either fasting glucose and insulin concentration or oral glucose tolerance test (OGTT). One of such indices is ratio of insulin to glucose concentration in fasting condition, i.e. IRI/G ratio. However, the most commonly HOMA-IR (Homeostasis Model Assessment of Insulin Resistance) index that is also calculated based on fasting concentration of insulin and glucose is used [4]. Moreover, one can use HOMA2-IR index and index of beta cell function $\beta$ HOMA-\%B (Homeostasis Model Assessment of $\beta$-cell Function) as well as insulin sensitivity index HOMA-\%S (Homeostasis Model Assessment of Insulin Sensitivity) that can be calculated using generally available HOMA2 calculator. Additional parameter used for assessment of insulin resistance is C-peptide concentration and increasing number of researchers points to appropriateness of its determination especially in young people [12].

Testing body fat quantity and distribution has become such a clinically important parameter that the International Diabetes Federation (IDF), in their "Platinum Standard" of additional tests related to metabolic syndrome, recommends analysis of body composition and body fat distribution using Dual-energy X-ray absorptiometry (DEXA) or computer tomography/magnetic resonance imaging (CT/MRI) [13]. These methods, although very accurate, are not widely available andare related to high costs and expose patient to unnecessary radiation [14]. There are few others methods for the measurement of body composition and assessment of the amount of body fat, among which the most commonly used is bioelectrical impedance analysis (BIA). The body composition test using BIA method is safe and can be conducted virtually regardless of health, age or sex. The BIA is a simple and minimally invasive method with high repeatability. The methods involves flow of low-intensity electric current and assessment of resistance of individual tissues. From the clinical perspective, systematic control of body composition allows effective monitoring of physical activity, diet used or applied therapy [15-17]. Additional advantage of the BIA is a short time of analysis, as well as easy-to-use, usually portable equipment [15].

In Poland obesity is diagnosed already in one of five young people and the number is constantly increasing. This is mainly related to the change in lifestyle, high-calorie diet as well as social and economic development. Due to the global problem, preventive actions are underway all over the world in order to reduce the development of obesity, particularly among young people. However, the literature contains little data on insulin resistance markers in the group age of young people with normal body weight that could be useful information in prevention of civilisation disease resulting from increase of body fat [18].

\section{Objective}

The objective of the study was to determine relation between insulin resistance index and selected parameters of body fat distribution using BIA in potentially healthy young females of body mass index below $25 \mathrm{~kg} / \mathrm{m}^{2}$

\section{Material and methods \\ Characteristics of study group}

The study group consisted of 36 young females, students of Wroclaw Medical University, aged 20 to 23 y.o. with $\mathrm{BMI}<25$, which did not report current health problems, chronic medication use and addictions. Additionally, none of the volunteers reported family history of metabolic diseases. The volunteers were informed about the purpose and the aim of the study and gave their written consent.

\section{Physical examination}

On the study day the volunteers came to the Teaching Medical Diagnostics Laboratory of the Wroclaw Medical University fasted, in early morning hours, i.e. between 7:30 and 8:30 AM. After completing the questionnaire, a physical examination was conducted involving height, weight, waist circumference, hip circumference and blood pressure measurement. Height, waist and hips circumference were measured with an accuracy of $0.5 \mathrm{~cm}$. Waist circumference was measured in the midway between lower abdomen quadrant and lower rib edge, while hips circumference at the greatest circumference of the thigh. Body weight was measured using medical scales without footwear and 
Table 1. Anthropometric characteristics and distribution of body mass of participants

\begin{tabular}{lcc}
\hline Parameter & Median & Q1-Q3 \\
\hline Anthropometric data & & \\
Height [cm] & 165.0 & $163.5-175.5$ \\
Body weight $[\mathrm{kg}]$ & 54.6 & $51.9-61.2$ \\
Age (years) & 22 & $21-23$ \\
Systolic blood pressure [mm Hg] & 110 & $105-117$ \\
Diastolic blood pressure [mm Hg] & 70 & $67-75$ \\
Waist circumference [cm] & 72.0 & $69.0-78.5$ \\
Hip circumference [cm] & 93.2 & $89.5-97.5$ \\
BMI [kg/m²] & 20.2 & $19.3-21.9$ \\
WHR & 0.78 & $0.76-0.82$ \\
Body composition parameters & & \\
Total fat mass [kg] & 12.3 & $10.4-16.6$ \\
Total fat mass (\%) & 23.0 & $20.6-27.2$ \\
Total body water [kg] & 31.2 & $29.6-33.5$ \\
Total body water (\%) & 56.4 & $53.2-58.2$ \\
Muscle mass [kg] & 40.4 & $38.2-43.5$ \\
Muscle mass (\%) & 73.2 & $68.8-75.4$ \\
Fat-free mass [kg] & 42.6 & $40.3-45.8$ \\
Fat-free mass (\%) & 76.9 & $72.5-79.4$ \\
Trunk fat mass [kg] & 5.8 & $4.4-8.5$ \\
Trunk fat mass (\%) & 10.6 & $8.8-13.9$ \\
\hline
\end{tabular}

$\mathrm{BMI}$ - body mass index, WHR - waist/hips ratio, Q1-Q3 - quartiles 1-3

outerwear. The blood pressure was measured twice using sphygmomanometer at rest; the statistical analysis was performed for averaged values. Moreover, for each person waste-hips ratio (WHR) and body mass index (BMI) were calculated.

\section{Body composition analysis}

Segmental body composition measurement was performed using the Tanita Model BC 418 MA analyser. The analyser, using 8 electrodes, allows precise estimation of body fat and body muscle in individual body segments, particularly of fat tissue located inside the abdominal cavity. The following values were used in statistical analysis: total fat mass (FM), trunk fat mass (TFM), total body water (TBW), muscle mass (MM) and fat free mass (FFM) (Tab. 1).

\section{Laboratory tests}

From all volunteers, in fasting conditions, venous blood was collected with $\mathrm{K}_{3}$ EDTA as an anticoagulant to obtain plasma and with coagulant activator in order to obtain serum. Then, among the volunteers, whose fasting glucose concentration in plasma was $<126 \mathrm{mg} / \mathrm{dl}$, oral glucose tolerance test was performed for $75 \mathrm{~g}$ of glucose.
The fasting samples were used for determination of the concentrations of: glucose, insulin, C-peptide, total cholesterol, triglycerides, HDL and LDL cholesterol. In the samples collected in 60 and 120 minute of the OGTT, concentrations of glucose and insulin were determined.

Glucose concentration in venous plasma was determined using enzymatic colorimetric method GOD-POD (Glucose GOD-POD, Thermo Fisher Scientific Inc., Vantaa, Finland); enzymatic colorimetric method was also applied for determination of triglycerides (Triglycerides, Thermo Fisher Scientific Inc., Vantaa, Finland), total cholesterol (Thermo Fisher Scientific Inc., Vantaa, Finland) and HDL cholesterol (Thermo Fisher Scientific Inc., Vantaa, Finland), while LDL cholesterol was calculated using Friedewald equation. Insulin and C-peptide were determined using immunoenzymatic assay (DRG Insulin and C-Peptide ELISA Kit, DRG Instruments $\mathrm{GmbH}$, Marburg, Germany). Metabolic characteristics of the study group is presented in Table 2.

For all the tests, appropriate control materials were used.

\section{Insulin resistance indices}

HOMA-IR index was calculated based on fasting concentrations of insulin and glucose using the formula:

HOMA-IR = fasting glucose concentration [mmol/L]

$\times$ fasting insulin concentration $[\mu \mathrm{IU} / \mathrm{mL}] / 22.5$

The study used also indices, modified by Levy et al., i.e. HOMA2-IR and HOMA2-\%B and HOMA2-\%S which were calculated using HOMA2 calculator available at the website of the Oxford Centre for Diabetes, Endocrinology and Metabolism (https://www.dtu.ox.ac. uk/homacalculator/). Moreover, fasting insulin $[\mu \mathrm{IU} / \mathrm{mL}]$ and glucose $[\mathrm{mg} / \mathrm{dL}]$ ratio was determined - IRI/G.

\section{Statistical analysis}

The statistical analysis was performed using software called Statistica 10 (StatSoft, Tulsa, USA). Distribution normality of the tested variables was verified by Shapiro-Wilk test and by using Levene's variance homogeneity test. In order to determine relation between analysed parameters, Pearson's linear correlation coefficient was applied - for parameters with normal distribution, or Spearman's ranks were applied - if variable distribution was not normal. For the verification procedures the assumed significance level was $p<0.05$.

Due to the fact that the majority of parameters did not have normal distribution, the results are presented as median and range between first and third quartile (Q1-Q3). 
Table 2. Metabolic characteristics of subjects

\begin{tabular}{|c|c|c|}
\hline Parameter & Median & Q1-Q3 \\
\hline \multicolumn{3}{|c|}{ Carbohydrate metabolism parameters } \\
\hline Fasting glucose [mmol/L] & 5.1 & $4.9-5.4$ \\
\hline Glucose $60^{\prime}[\mathrm{mmol} / \mathrm{L}]$ & 5.3 & $4.6-6.4$ \\
\hline Glucose $120^{\prime}[\mathrm{mmol} / \mathrm{L}]$ & 5.1 & $4.4-5.9$ \\
\hline Fasting insulin $[\mu \mathrm{lU} / \mathrm{mL}]$ & 10.8 & $9.2-14.0$ \\
\hline [pmol/L] & 65 & $55-84$ \\
\hline Insulin $60^{\prime}[\mu \mathrm{IU} / \mathrm{mL}]$ & 55.5 & $34.4-84.3$ \\
\hline [pmol/L] & 333 & $206-506$ \\
\hline Insulin $120^{\prime}[\mu \mathrm{IU} / \mathrm{mL}]$ & 44.3 & $28.5-67.6$ \\
\hline$[\mathrm{pmol} / \mathrm{L}]$ & 266 & $171-406$ \\
\hline C-peptide $[\mathrm{nmol} / \mathrm{L}]$ & 1.16 & $0.60-1.69$ \\
\hline \multicolumn{3}{|c|}{ Indirect insulin resistance indices } \\
\hline $\mathrm{IRI} / \mathrm{G}$ & 0.1 & $0.1-0.2$ \\
\hline HOMA-IR & 2.4 & $2.1-3.2$ \\
\hline HOMA2-IR & 1.4 & $1.2-1.8$ \\
\hline HOMA2-\%B & 124.5 & $102.6-137.4$ \\
\hline HOMA2-\%S & 72.1 & $55.2-84.6$ \\
\hline \multicolumn{3}{|c|}{ Lipid metabolism parameters } \\
\hline Total cholesterol $[\mathrm{mmol} / \mathrm{L}]$ & 4.30 & $3.78-4.87$ \\
\hline HDL cholesterol [mmol/L] & 1.53 & $1.42-1.71$ \\
\hline LDL cholesterol [mmol/L] & 2.49 & $1.94-2.74$ \\
\hline Triglycerides [mmol/L] & 0.70 & $0.60-1.17$ \\
\hline C-reactive protein & 0.7 & $0.2-1.7$ \\
\hline
\end{tabular}

CRP - C-reactive protein, HOMA-IR - Homeostasis Model Assessment of Insulin Resistance, HOMA2-IR - Homeostasis Model Assessment, version 2, HOMA2-\%B - Homeostasis Model Assessment of $\beta$-cell Function, HOMA2-\%S - Homeostasis Model Assessment of Insulin Sensitivity, IRI/G — insulin/glucose ratio, Q1-Q3 - quartiles 1 and 3

\section{Results}

Anthropometric characteristics and body mass distribution of tested volunteers are presented in Table 1. The total body fat mass for 25-75 percentile in the tested group was in the range of 10.4-16.6 [kg]. However, the relative body fat mass exceeding acceptable percentage for age and sex of $>30 \%$ was observed in 3 women (8.3\%) despite correct values of BMI (median: 20.2 - with maximum: 24.6). Central obesity measured as waist circumference $\geq 80 \mathrm{~cm}$ was found in $22.2 \%$ women. All the parameters of body fat distribution (both absolute and relative values) were correlated with waist circumference significantly, while the most significant correlation coefficient was found for trunk fat mass (WC vs. TFM $r=0.657, p<0.001$ ).

Table 2 presents metabolic characteristics of the tested group and the most popular insulin resistance indices. Under the basic conditions, glucose and insulin concentration were in range of reference values, while for glucose those were so-called high normal values (> $4.9 \mathrm{mmol} / \mathrm{L}) .21$ women $(58.3 \%)$ presented an increased fasting concentration of C-peptide (1.05 $\mathrm{nmol} / \mathrm{L}$ ) whereas, over $3.31 \mathrm{nmol} / \mathrm{L}$ was found in three of them. In turn, for such parameters as: total cholesterol, HDL and LDL cholesterol, triglycerides and CRP, no values outside the allowable concentration range were found. In all tested volunteers normal glucose tolerance in 120 minute of the OGTT [19] and normal values of IRI/G ration were observed. Interestingly, in the tested group, a relatively high median of HOMA-IR index was found, equal to 2.4. At the same time it was found that the studied group had normal function of pancreas beta cells (HOMA2-\%B), with median of insulin sensitivity index HOMA2-\%S being 72.1.

It is surprising that fasting glucose concentration had negative correlation with total fat mass $(r=-0.404$; $p=0.015)$, and also with absolutetrunkfatmass $(r=-0.417$; $p=0.012$ ). C-peptide, however, was significantly correlated with total fat mass $(r=0.532 ; p=0.001)$ and trunk fat mass $(r=0.471 ; p=0.004)$ (Fig. 1). Moreover, relative value of FM was correlated with C-peptide ( $r=0.362$; $p=0.030)$ and similar significance was found for TFM percentage and HOMA2-\%B ( $r=0.356 ; p=0.033)$. There was no correlation between insulin concentration in any point of OGTT, for both absolute and relative values, observed (Tab. 3).

\section{Discussion}

The World Health Organisation (WHO) places great emphasis on prevention of civilisation diseases, which are the consequence of development of tissue insulin resistance, including diabetes, cardiovascular diseases and metabolic syndrome [1, 2]. Despite that, in databases such as PubMed there is a rather small number of papers relating to young, potentially healthy people, for whom probability of insulin resistance was verified in correlation with selected parameters of fat tissue [20]. Moreover, in such health conditions as polycystic ovary syndrome, insulin resistance in slim women is observed in $30 \%$ of cases, while for obese women this value reaches up to $80 \%$. Due to that, constant monitoring of fat mass and fat distribution in correlation with tissue insulin resistance indices seems to be crucial for women of childbearing age [9].

The recognised factor of development of insulin resistance is increase in total fat mass, especially in the abdomen part $[21,22]$. In the last several years it was shown that central obesity is a better predictor of development of insulin resistance that commonly used body mass index. It is recommended that evaluation of central obesity, expressed as waist circumference, shall be used in clinical practice for assessment of risk of development of type 2 diabetes, even in people with BMI $<25 \mathrm{~kg} / \mathrm{m}^{2}$ [23]. Waist circumference measurement 

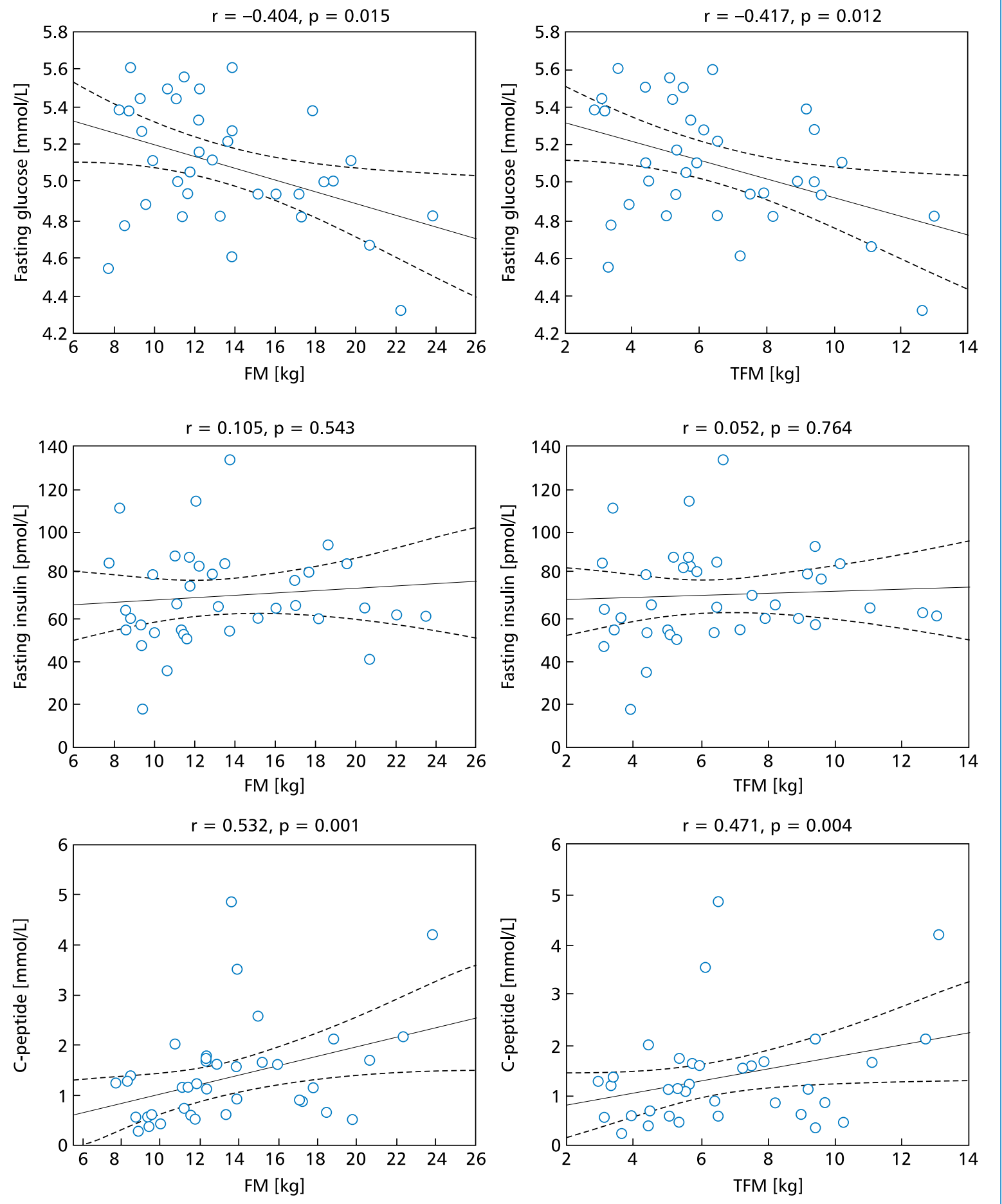

Figure 1. Plots of value scatter for fasting glucose, insulin and C-peptide in correlation with total fat mass [kg] and trunk fat mass $[\mathrm{kg}]$

used for diagnosis of metabolic disease is continuously assessed, and becomes more and more rigorous parameter determined separately for each population. Currently, for the European women according to the IDF criteria, this value is $\geq 80 \mathrm{~cm}[1,13]$. In the examined group of volunteers, WC median was $72 \mathrm{~cm}$, while cen- tral obesity measured according to waist circumference was found in 8 women $(22.2 \%)$, whereas it must be noted that maximum WC was $89 \mathrm{~cm}$. Despite the small group, the values are similar to the values obtained by Miazgowski et al. (26.2\%), who studied a group of 145 young women from Polish population [22]. 
Table 3. Correlations of total fat mass (FM) and trunk fat mass (TFM) with indicators of insulin resistance. Correlations of total fat mass (FM) and trunk fat mass (TFM) with indicators of insulin resistance

\begin{tabular}{|c|c|c|c|c|c|c|c|c|}
\hline \multirow[t]{3}{*}{ Parameter } & \multicolumn{4}{|c|}{ FM } & \multicolumn{4}{|c|}{ TFM } \\
\hline & \multicolumn{2}{|c|}{ [kg] } & \multicolumn{2}{|c|}{ (\%) } & \multicolumn{2}{|c|}{$[\mathrm{kg}]$} & \multicolumn{2}{|c|}{ (\%) } \\
\hline & $r$ & $p$ & $r$ & $p$ & $r$ & $p$ & $r$ & $p$ \\
\hline Fasting glucose & -0.404 & 0.015 & -0.236 & 0.166 & -0.417 & 0.012 & -0.322 & 0.055 \\
\hline Glucose 60' & -0.149 & 0.386 & -0.184 & 0.282 & -0.297 & 0.078 & -0.262 & 0.123 \\
\hline Glucose 120' & -0.075 & 0.665 & -0.127 & 0.459 & -0.203 & 0.234 & -0.193 & 0.260 \\
\hline Fasting insulin & 0.105 & 0.543 & 0.187 & 0.275 & 0.052 & 0.764 & 0.187 & 0.276 \\
\hline Insulin 60' & -0.003 & 0.987 & -0.027 & 0.874 & -0.120 & 0.485 & -0.085 & 0.622 \\
\hline Insulin 120' & -0.040 & 0.819 & 0.254 & 0.134 & -0.136 & 0.431 & 0.267 & 0.116 \\
\hline IRI/G ratio & 0.299 & 0.077 & -0.048 & 0.780 & 0.270 & 0.111 & -0.108 & 0.530 \\
\hline HOMA-IR & 0.116 & 0.499 & 0.103 & 0.548 & 0.091 & 0.596 & 0.085 & 0.623 \\
\hline HOMA-\%S & -0.203 & 0.234 & -0.169 & 0.325 & -0.167 & 0.332 & -0.156 & 0.364 \\
\hline НОМА-\%B & 0.396 & 0.017 & 0.327 & 0.052 & 0.363 & 0.029 & 0.356 & 0.033 \\
\hline HOMA2-IR & 0.219 & 0.199 & 0.175 & 0.307 & 0.170 & 0.323 & 0.166 & 0.335 \\
\hline C-Peptide & 0.532 & 0.001 & 0.362 & 0.030 & 0.471 & 0.004 & 0.314 & 0.062 \\
\hline
\end{tabular}

Pearson's linear correlation coefficients were used for parameters with normal distribution, while Spearman's ranks were applied, if variable distribution was not normal

In medical practice, BMI is still used for expressing estimated fat mass, despite its limitations. Its main limitation is the lack of distinction between fat mass and muscle mass $[23,24]$ as well as the fact that it gives no information on body fat distribution [25]. Therefore, there is an increasing trend of recommending body composition measurements, especially using generally available techniques such as BIA. In our studies we have also observed a strong correlation between $\mathrm{BMI}$ and FM $(r=0.756 ; p<0.001)$ and a negative correlation between BMI and MM $(r=-0.764 ; p<0.001)$. Accurate estimation of fat and muscle mass in individual body segments, particularly visceral adipose tissue located inside the abdominal cavity, allows precise determination of health risks related to development of tissue insulin resistance.

In clinical practice, commonly used insulin resistance indices involve simultaneous determination of glucose and insulin concentration, in basic conditions or during functional tests (mainly OGTT). The determined values can be used for calculation of so-called indirect insulin resistance indices. The simplest one is a ratio of fasting blood concentration of insulin [mIU/L] and glucose $[\mathrm{mg} / \mathrm{dL}]-\mathrm{IRI} / \mathrm{G}$. The decisive value suggesting insulin resistance is $>0.3$ [26]. All the tested volunteers presented normal values of IRI/G ratio. Moreover, in the tested group there was no significant correlation found for IRI/G ratio with the total or trunk fat mass.

Another indirect insulin resistance index is a mathematical model HOMA-IR, evaluating relation between generation of glucose in the liver and function of pancreas beta cells that regulate concentration of glucose and insulin. HOMA-IR reflects mainly insulin sensitivity in fasted conditions and, to a limited extent, a possibility of determination of insulin resistance after meal [27]. Matthews et al. [28] presented a strong correlation between HOMA-IR and insulin sensitivity index determined by means of hyperinsulinemic-euglycemic clamp, which is recognised as golden standard for assessment of insulin resistance. Due to the complexity and invasiveness of the method and high costs of the procedure, the technique is not appropriate for epidemiology studies, therefore routine diagnostics uses indirect insulin resistance indices, including HOMA-IR [29]. The value of HOMA-IR for young people with normal body mass in ideal conditions should be 1.0. However, this index depends on many factors, including age, sex, ethnicity or fat mass, therefore it is difficult to establish cutoff of HOMA-IR, which have to be determined separately for each population [30]. Moreover, this parameter has certain clinical limitations, especially for people with impaired glucose tolerance [27]. For Polish population cutoff of HOMA-IR was determined among others by Szurkowska et al. They determined its value, for which insulin resistance can be diagnosed, as the upper quartile of distribution in population of normal glucose tolerance and normal body weight, i.e. HOMA-IR $>2.1$ [31] while Żyła [30] has adopted value $\geq 2.5$. By cutoff value of HOMA-IR $\geq 2.5$, insulin resistance could be diagnosed in over $47 \%$ of tested volunteers. However, assuming that the study group consisted of 
potentially healthy people of normal body weight and adopting insulin resistance diagnosis cutoff based on HOMA-IR - upper quartile, the value would be $\geq 3.2$. This is a value close to Q3 of the entire group tested by Szurkowska et al., which greatly shifts the cutoff value for insulin resistance diagnosis in our population.

All the tested women had normal fat mass for their sex, age and ethnicity. The body fat mass increases with age. Age median of our volunteers was 10 years lower than for group tested by Miazgowski et al. [22], and despite comparable BMIs and fat-free mass (so-called lean mass), fat mass in our group is lower. This can be also a result of the equipment used in this study and its accuracy in comparison with reference method [15].

It seems interesting that trunk fat mass is correlated negatively with fasting concentration of glucose $(r=-0.417 ; p=0.014)$. In volunteers participating in the study, normal fasting glucose concentrations were found, but those were high values (median $5.1 \mathrm{mmo} / \mathrm{l}$ ). However, there was no dependence found for fasting insulin nor any other insulin resistance indices in relation to trunk fat mass while correlation of C-peptide with the total body fat mass was found to be significantly positive $(r=0.532 ; p=0.005)$. C-peptide is synthesised by pancreas beta cells in equimolar quantities in relation to insulin, but due to the longer half-life, C-peptide concentrations in fasting conditions were five times higher than for insulin. C-peptide determination allows evaluation of current functional conditions of pancreas beta cells and is very useful parameter prior to development of overt insulin resistance [32]. Therefore, in potentially healthy people, from a diagnostic perspective, C-peptide seems a more adequate parameter than insulin for determination of function of pancreas beta cells. Moreover, Min et al. has found that C-peptide is a better predictor of risks of complications of cardiovascular and coronary artery disease than the glycated hemoglobin, or concentration of glucose in fasting conditions [12].

Our research, although conducted on a relatively small group of subjects, provides results justify its continuation on extended young people population, especially regarding the diagnostic importance of C-peptide as one of parameters of tissue insulin resistance development.

\section{Conclusions}

In young, non-obese women there is a significant correlation between total and trunk body fat and fasting C-peptide concentration. There was no such correlation for insulin and FM or TFM, in any of the three timepoints of the OGTT. Therefore, during the assessment of insulin resistance risk in young people, next to routinely performed glycemia assays, it seems justified to perform additional determination of C-peptide concentration and regular examination of total fat mass, with special emphasis on trunk fat mass. As it turns out, calculation of BMI may be definitely insufficient for determination of cardiometabolic risks in young women, as every fifth subject with normal BMI had abnormal waist circumference. And as the study shows, it is the trunk fat mass that is significantly correlated with C-peptide. At the time of diabetes epidemic, early diagnosis of disturbances in carbohydrate metabolism and determination of risk of development of insulin resistance in young, potentially healthy persons is a crucial action for preventing development of civilisation diseases.

\section{REFERENCES}

1. Alberti KG, Eckel RH, Grundy SM et al. Harmonizing the metabolic syndrome: a joint interim statement of the International Diabetes Federation Task Force on Epidemiology and Prevention; National Heart, Lung, and Blood Institute; American Heart Association; World Heart Federation; International Atherosclerosis Society; and International Association for the Study of Obesity. Circulation 2009; 120: 1640-1645.

2. Obesity: preventing and managing the global epidemic. Report of a WHO consultation. World Health Organ. Tech Rep Ser 2000; 894: i-xii, 1-253.

3. Hu G, Qiao Q, Tuomilehto J, Balkau B, Borch-Johnsen K, Pyorala K. Prevalence of the metabolic syndrome and its relation to all-cause and cardiovascular mortality in nondiabetic European men and women. Arch Intern Med 2004; 164: 1066-1076.

4. Szulińska M, Kujawska-Łuczak M, Bogdański P, Pupek-Muszalik D. Wskaźnik insulinowrażliwości M i wskaźnik IRI/G w ocenie insulinooporności u pacjentów z nadciśnieniem tętniczym i otyłością. Arterial Hypertention 2010; 14: 142-150.

5. Abdullah A, Hasan H, Raigangar V, Bani-Issa W. C-peptide versus insulin: relationships with risk biomarkers of cardiovascular disease in metabolic syndrome in young arab females. Int J Endocrinol 2012; 2012: 420792.

6. Gennarelli G, Rovei V, Novi RF et al. Preserved insulin sensitivity and beta-cell activity, but decreased glucose effectiveness in normal-weight women with the polycystic ovary syndrome. J Clin Endocrinol Metab 2005; 90: 3381-3386.

7. Bianco A, Pomara F, Thomas E et al. Type 2 diabetes family histories, body composition and fasting glucose levels: a cross-section analysis in healthy sedentary male and female. Iran J Public Health 2013; 42: 681-690.

8. Hsieh CJ, Wang PW, Chen TY. The relationship between regional abdominal fat distribution and both insulin resistance and subclinical chronic inflammation in non-diabetic adults. Diabetol Metab Syndr 2014; 6: 49.

9. Ozegowska KE, Pawelczyk LA. The role of insulin and selected adipocytokines in patients with polycystic ovary syndrome (PCOS) - a literature review. Ginekol Pol 2015; 86: 300-304.

10. Celik N, Evsen MS, Sak ME, Soydinc E, Gul T. Evaluation of the relationship between insulin resistance and recurrent pregnancy loss. Ginekol Pol 2011; 82: 272-275.

11. Craig LB, Ke RW, Kutteh WH. Increased prevalence of insulin resistance in women with a history of recurrent pregnancy loss. Fertil Steril 2002; 78: 487-490.

12. Min JY, Min KB. Serum C-peptide levels and risk of death among adults without diabetes mellitus. CMAJ 2013; 185: E402-E408. 
13. http: //www.idf.org/webdata/docs/IDF_Meta_def_final.pdf.

14. Cyganek K, Katra B, Sieradzki J. Porównanie pomiarów tkanki tłuszczowej u otyłych pacjentów z zastosowaniem metody bioimpedancji elektrycznej i densytometrycznej. Diabetol Prakt 2007; 8: 473-478.

15. Demura S, Sato S, Kitabayashi T. Percentage of total body fat as estimated by three automatic bioelectrical impedance analyzers. J Physiol Anthropol Appl Human Sci 2004; 23: 93-99.

16. Bosaeus M, Karlsson T, Holmang A, Ellegard L. Accuracy of quantitative magnetic resonance and eight-electrode bioelectrical impedance analysis in normal weight and obese women. Clin Nutr 2014; 33: 471-477.

17. Gába A, Kapus O, Cuberek R, Botek M. Comparison of multi- and single-frequency bioelectrical impedance analysis with dual-energy X-ray absorptiometry for assessment of body composition in postmenopausal women: effects of body mass index and accelerometerdetermined physical activity. J Hum Nutr Diet 2015; 28: 390-400.

18. Placzkowska S, Pawlik-Sobecka L, Kokot I, Piwowar A. Incidence of complex metabolic disorders among young people - preliminary report. Pol Merkur Lek 2014; 37: 269-273.

19. Polskie Towarzystwo Diabetologiczne. Zalecenia kliniczne dotyczące postępowania u chorych na cukrzycę 2014. Stanowisko Polskiego Towarzystwa Diabetologicznego. Diabetol Klin 2014; 3 (suppl A).

20. Boutcher SH, Dunn SL, Gail Trapp E, Freund J. Regional adiposity distribution and insulin resistance in young Chinese and European Australian women. Scand J Clin Lab Invest 2011; 71: 653-657.

21. Rattarasarn $C$, Leelawattana $R$, Soonthornpun $S$ et al. Relationships of body fat distribution, insulin sensitivity and cardiovascular risk factors in lean, healthy non-diabetic Thai men and women. Diabetes Res Clin Pract 2003; 60: 87-94.

22. Miazgowski T, Major-Goluch A, Safranow K. Selected adipokines and metabolic profiles in normal-weight women with abdominal obesity. Pol Arch Med Wewn 2012; 122: 406-412.

23. Li S, Xiao J, Ji L et al. BMI and waist circumference are associated with impaired glucose metabolism and type 2 diabetes in normal weight Chinese adults. J Diabetes Complications 2014; 28: $470-476$

24. Kim CH, Kim HK, Kim EH, Bae SJ, Park JY. Association between changes in body composition and risk of developing type 2 diabetes in Koreans. Diabet Med 2014; 31: 1393-1398.

25. Li Y, Meng L, Sato Y. Associations of serum C-peptide level with body fat distribution and ever stroke in nondiabetic subjects. J Stroke Cerebrovasc Dis 2014; 23: e163-e169.

26. Wesołowski P, Wańkowicz Z. Insulinooporność - metody rozpoznawania i następstwa kliniczne. Nephrol Dial Pol 2011; 15 : 243-246.

27. Ferrara CM, Goldberg AP. Limited value of the homeostasis model assessment to predict insulin resistance in older men with impaired glucose tolerance. Diabetes Care 2001; 24: 245-249.

28. Matthews DR, Hosker JP, Rudenski AS, Naylor BA, Treacher DF, Turner RC. Homeostasis model assessment: insulin resistance and beta-cell function from fasting plasma glucose and insulin concentrations in man. Diabetologia 1985; 28: 412-419.

29. Bonora E, Targher G, Alberiche $M$ et al. Homeostasis model assessment closely mirrors the glucose clamp technique in the assessment of insulin sensitivity: studies in subjects with various degrees of glucose tolerance and insulin sensitivity. Diabetes Care 2000; 23: 57-63.

30. Żyła ZG. Insulin resistance and selected metabolic, inflammatory and anthropometric parameters in the adult population of the Tarnawa Dolna municipality in the Bieszczady. Przegl Kardiodiabetol 2011; 6: 243-249.

31. Szurkowska M, Szafraniec K, Gilis-Januszewska A, Szybiński Z, Huszno B. Wskaźniki insulinooporności w badaniu populacyjnym i ich wartość predykcyjna w określeniu zespołu metabolicznego. Przegl Epidemiol 2005; 59: 743-751.

32. Jones AG, Hattersley AT. The clinical utility of C-peptide measurement in the care of patients with diabetes. Diabet Med 2013; 30: 803-817. 